\title{
Despertando A Consciência Ambiental Na Escola Por Meio Da Resolução De Problemas
}

\section{Arising Environmental Awareness At School Through Problem Solving}

\author{
Cláudio Cristiano Liell \\ Universidade Luterana do Brasil - (ULBRA) \\ Arno Bayer \\ Universidade Luterana do Brasil - (ULBRA)
}

\begin{abstract}
Resumo
O presente estudo, parte de uma pesquisa de doutorado, apresenta os resultados do desenvolvimento de situaçõesproblema envolvendo temas ambientais com alunos dos anos finais do Ensino Fundamental no município de São Sebastião do Cai - RS. Os problemas, que foram elaborados em uma formação continuada em Educação Ambiental e Educação Matemática proporcionada a professores de matemática, abordaram a temática da água, dos resíduos, da poluição, da fauna, da vegetação, da energia, das áreas de preservação permanente - APP e envolveram os conteúdos de regra de três, porcentagem, proporção, operações com números naturais, perímetro, áreas e medidas de comprimento, massa e volume. As situações utilizadas pelos professores participantes da formação e seus alunos, provocaram nos estudantes a percepção da necessidade de reformularem os hábitos e os cuidados com o meio ambiente e, também, conseguiram despertar o interesse pela matemática, pois ela passou a ser vista por eles, como uma ferramenta útil e indispensável, que pode utilizada e aplicada na resolução de temas variados, dando subsídios para interpretação de fatos que ocorrem ao nosso redor.
\end{abstract}

Palavras-chave: Resolução de Problemas. Temas Ambientais. Consciência Ambiental

\begin{abstract}
This study, part of a doctoral research, presents the results of development of problem situations involving environmental issues with students of elementary School of São Sebastião do Caí-RS. The problems were created in a continued formation in environmental education and math education provided to math teachers, addressed the theme of water, waste, pollution, wildlife, vegetation, energy, the areas of APP and involved the contents of statistics, rule of three, percentage, proportion, operations with natural numbers, perimeter, area and measures of length, mass and volume. The situations used by teachers participating of the formation and their students, bring in the students the perception of the need to reformulate the habits and care with the environment and also, it was able to arouse interest in mathematics, because it has come to be seen by them, as a useful and indispensable tool that can be used and applied in the resolution of varied themes, giving subsidies for the interpretation of facts that occur around us.
\end{abstract}

Keywords: Resolution of Problems. Environmental Issues. Environmental Awareness 


\section{Introdução}

$\mathrm{Na}$ atualidade, o homem passou a ter um estilo de vida que levou à formação de um mundo com desequilíbrios, gerando degradação ambiental e social e não há consenso sobre como construir um desenvolvimento que integre justiça social, sustentabilidade ambiental e viabilidade econômica.

A educação tem um papel primordial nesse sentido, pois pode contribuir decisivamente com ações pedagógicas e com modelos de ensino que atendam às modificações que a sociedade passou a exigir e que visem à formação de pessoas capazes de refletir sobre questões sócioambientais.

No entanto, o trabalho com a questão ambiental nas aulas resulta, não apenas numa preocupação, mas também em um problema, pois, segundo Meyer (2000), depara-se com a falta de formação e de conhecimento dos professores para um trabalho efetivo nessa área.

A problemática levantada, originou um projeto de doutorado para responder ao seguinte questionamento: uma formação continuada em educação ambiental e educação matemática poderia influenciar nas práticas de sala de aula dos professores de Matemática com essa mesma proposta temática e contribuir para o desenvolvimento da consciência ambiental nos alunos?

Considerando o contexto acima, foi organizada e oportunizada uma formação continuada em Educação Ambiental e Matemática aos professores de matemática dos anos finais do Ensino Fundamental do município de São Sebastião do Cai, com o objetivo de verificar se os envolvidos modificariam a concepção de Educação Ambiental e as práticas de sala de aula em relação aos temas ambientais.

Dentre as atividades dessa formação, que serão apresentadas neste estudo, destacaramse os resultados do desenvolvimento de situações-problema que relacionam conteúdos matemáticos e temáticas ambientais nas turmas dos educadores envolvidos. Portanto, esta pesquisa trará as contribuições da aplicação dessas situações para a formação da consciência ${ }^{1}$

\footnotetext{
${ }^{1}$ Dias (2001), destaca que a Educação Ambiental, segundo recomendações da Conferência Intergovernamental de Tbilisi de 1977, deve promover a consciência, ou seja, trabalhar para que os indivíduos, sejam sensibilizados e conscientizados de tudo que acontece ao seu redor. Já para o PCN Meio Ambiente, o trabalho escolar com o tema é contribuir para a formação de cidadãos conscientes, capazes para decidirem e atuarem na realidade socioambiental de um modo comprometido com a vida e com o bem-estar das pessoas. Ainda, segundo o PCN Meio Ambiente, “[...] o trabalho de Educação Ambiental deve ser desenvolvido a fim de ajudar os alunos a construírem uma consciência global das questões relativas ao meio para que possam assumir posições afinadas com os valores referentes à sua proteção e melhoria" (BRASIL, 1997, p.35).
} 
ambiental nos alunos e para a sensibilização ${ }^{2}$ sobre os cuidados com o meio ambiente

\title{
2 A Resolução de Problemas
}

\begin{abstract}
Um dos principais objetivos do ensino da matemática é fazer o aluno pensar produtivamente e, para isso, nada melhor que apresentar-lhe situações- problema que o envolvam, o desafiem e o motivem a querer resolvê-las. Esta é uma das razões pela qual a resolução de problemas tem sido reconhecida no mundo todo como uma das metas fundamentais da matemática no $1^{\circ}$ grau. (DANTE, 1991, p.11)
\end{abstract}

Os educadores matemáticos têm estudado desde 1980 a formulação e a resolução de problemas, devido à sua grande importância para a aprendizagem da matemática. Alguns especialistas chegam a considerar a tendência à resolução de problemas no Ensino Fundamental, como a principal razão de se aprender e se ensinar matemática, pois é por meio dela que se inicia o aluno no modo de pensar e de aplicar matemática.

Nos dias atuais, tem se exigido cada vez mais indivíduos pensantes e que saibam interligar os saberes que possuem. No entanto, parece que a educação escolar não vem favorecendo muito para que isso aconteça, pois com relação ao ensino da Matemática nas escolas, percebe-se a priorização pelo ensino de regras e a aplicação de fórmulas adequadas para encontrar determinadas respostas.

É preciso quebrar a dicotomia entre a forma como essa disciplina é ensinada nas escolas e aquela que é utilizada na resolução dos problemas do dia a dia. Para isso, será necessário contextualizar os ensinamentos matemáticos, relacionando-os com a realidade vivenciada pelos alunos, por meio de temas que sejam atuais ou de interesse dos alunos.

A solução de problemas baseia-se na apresentação de situações abertas e sugestivas que exijam dos alunos uma atitude ativa ou um esforço para buscar suas próprias respostas, seu próprio conhecimento. O ensino baseado na solução de problemas pressupõe promover nos alunos o domínio de procedimentos, assim como a utilização dos conhecimentos disponíveis, para dar resposta a situações variáveis e diferentes (POZO e ECHEVERRÍA, 1988, p. 9).

Pozo e Echeverria (1988) também destacam que, para ensinar a resolver problemas, não é suficiente prover os alunos de habilidades e estratégias eficazes, mas é importante

\footnotetext{
${ }^{2}$ Conforme Sato (2003), a sensibilização é definida como um processo de alerta, primeiro objetivo para alcançar o pensamento sistêmico da educação ambiental. Para Medina (2000), ela também é uma etapa inicial da Educação Ambiental, e é necessária para que as pessoas sejam tocadas pelas belezas da natureza ou dos graves problemas ambientais de lixo ou de contaminação, por exemplo.
} 
desenvolver neles a atitude de enfrentar a aprendizagem como um problema para o qual deve ser encontrada uma resposta.

Segundo Dante (1988), os problemas deveriam estar interligados a fatos e acontecimentos do cotidiano do aluno, portanto, jornais, revistas, anúncios de venda de imóveis, pesquisas de opinião, erros de impressão, entre tantos outros, podem ser utilizados.

É, pois, fundamental que o estudo da Matemática seja calcado em situaçõesproblema que possibilitem a participação ativa na construção do conhecimento matemático. O aluno desenvolve seu raciocínio participando de atividades, agindo e refletindo sobre a realidade que o cerca, fazendo uso das informações de que dispõe. Se quisermos melhorar o presente estado de conhecimento, devemos nos questionar sobre como pode, de fato o nosso aluno desenvolver o pensamento crítico ou raciocínio lógico (SMOLE e CENTURIÓN, 1992, p. 9).

Para Lopes (1994), os professores, ao elaborarem o trabalho com a resolução de problemas:

...devem estabelecer claramente os objetivos que pretendem atingir. Para se desenvolver uma boa atividade, o que menos importa é saber se um problema é de aplicação ou de quebra-cabeça. O principal é analisar o potencial do problema no desenvolvimento de capacidades cognitivas, procedimentos e atitudes e na construção de conceitos e aquisição de fatos da Matemática. O melhor critério para organizar um repertório é selecionar, ou mesmo formular, problemas que possibilitem aos alunos pensar sobre o próprio pensamento, que os coloquem diante de variadas situações (LOPES, 1994, p. 40).

Já Onuchic (1999), afirma que,

quando os professores ensinam matemática através da resolução de problemas, eles estão dando a seus alunos um meio poderoso e muito importante de desenvolver sua própria compreensão. À medida que a compreensão dos alunos se torna mais profunda e mais rica, sua habilidade em usar matemática para resolver problemas aumenta consideravelmente (ONUCHIC, 1999, p.207)

A apresentação de uma situação-problema ao aluno aprofunda a compreensão de conceitos já existentes e favorece a formação de outros. Através da resolução de problemas é desenvolvida a autoconfiança dos alunos, aumentando neles a desenvoltura de resolução de problemas matemáticos em situações novas e fazendo evoluir a capacidade de raciocinar e de interpretar.

\section{A Aprendizagem Matemática e a Educação Ambiental}

Segundo Búrigo (2009), a Matemática não pode mais continuar a ser vista como um 
assunto linear, preocupado essencialmente com fatos e capacidades, como uma ciência relativa predominantemente a números, ensinada mecanicamente e caracterizada geralmente por atividades de papel e lápis. Ela deve, além de proporcionar uma alfabetização matemática voltada para o entendimento das influências que a disciplina exerce no meio científico, tecnológico e social, também ter uma abordagem que articule os conhecimentos entre si de forma reflexiva.

Deve-se considerar que o aluno chega à escola trazendo uma cultura construída na comunidade em que vive, e o professor deverá levar em conta esse fato no preparo de suas aulas, pois, segundo Maccarani (2007), a Educação Matemática visa à formação do aluno como um todo, utilizando o conhecimento matemático integrado às demais áreas de conhecimento, a partir da realidade em que o aluno está inserido e também, em um determinado contexto.

O grande desafio dos educadores matemáticos, está em priorizar o aluno em primeiro plano, fazendo com que o ensino dessa disciplina contribua para que esse aluno tenha uma visão mais crítica da realidade. Essa contribuição não se dará apenas através do conteúdo aprendido, mas também, segundo Caldeira (2001), por sua inserção numa dimensão política na forma de sua transmissão e assimilação.

A interação dos conhecimentos adquiridos pelos alunos na sua vivência com os conhecimentos decorrentes da ação educativa da escola, enriquecida por discussões a respeito de implicações sociais, ambientais, políticas, entre outras, oportunizará aos estudantes as condições para a sua atuação crítica no dia a dia.

Infelizmente, em decorrência das práticas fragmentadas, há uma distância muito grande entre o que é ensinado nas escolas e o que é utilizado para resolver situações cotidianas, logo, o educando é apenas um observador de sua realidade e não um ser atuante e transformador desta. Uma proposta de ensino da Matemática voltada para as questões ambientais através da resolução de problemas, poderia ser uma alternativa para quebrar com essa grande diferença entre o ensinar e o fazer matemática.

No entanto, a ausência de uma formação específica em educação ambiental para os professores, reflete a dificuldade de realização de trabalhos na escola voltados para essa temática, estimulando ainda mais um processo de aprendizagem fragmentado. Muitas leituras indicam que isso ocorre devido a uma formação ou a uma especialização que não ampliam seu campo de investigação para além das fronteiras do saber disciplinar, pensamento que é corroborado por Cifuentes e Prestini (2006, p. 46), quando afirmam que essa dificuldade 
decorre da própria formação do professor, uma vez que "os professores têm que pensar e colocar em prática uma proposta que eles próprios não vivenciaram em momento algum de suas vidas".

Para Costa (2009), há um déficit na formação dos educadores nos cursos de licenciatura, no que se refere ao trabalho com a educação ambiental, e a solução estaria em fornecer aos professores uma formação por meio da ambientalização curricular da Educação Ambiental.

Segundo Freire (1996), deveria ser estabelecida uma intimidade entre os saberes curriculares fundamentais dos alunos e a experiência social que eles têm como indivíduos, pois, assim, essa preocupação ambiental se tornaria contextualizada e o aluno passaria a ser ativo no contexto social e um cidadão consciente de suas ações. Portanto, a abordagem dos conteúdos programáticos precisa levar em consideração as diversidades sociais, culturais e ambientais dos alunos.

Conforme recomendação da Conferência de Tbilisi (UNESCO, 1997), a Educação Ambiental deve estar voltada para a "resolução de problemas ambientais locais/concretos" e constituir-se em "tema gerador" para discussão da sociedade sobre o modo de produzir e consumir coisas.

Para Novicki (2006), a resolução de problemas ambientais locais/concretos, como uma situação de aprendizagem, deveria estar relacionada à seguinte competência para ensinar: envolver o alunos em atividades de pesquisa e projetos de conhecimento para a construção e desconstrução de saberes e a sua transformação.

Ao utilizarem nas aulas de matemática o Tema Transversal Meio Ambiente, os professores não estarão apenas fornecendo aos estudantes instrumentos para compreensão de fenômenos, mas também oferecendo subsídios através do uso da matemática no cotidiano ambiental, para que percebam o seu verdadeiro papel como cidadãos e transformadores sociais. Essa interação entre conhecimento matemático e as questões ambientais na busca de uma melhor compreensão do local em que vivemos, faz com que o aprendizado da matemática e do saber ambiental seja significativo e transforme o comportamento das pessoas, com o propósito de promover uma melhor qualidade de vida.

Essa nova forma de trabalhar em sala de aula permite aos estudantes serem sujeitos do processo; desenvolverem a condição de ouvir o outro; refletirem a partir do saber existente em direção à construção constante do saber; perceberem o professor como organizador e coordenador do processo; enfim, construírem uma cultura do saber e do saber fazer com o saber.

O professor, permanecendo alinhado com a perspectiva de trabalho sugerida, estará exercendo um trabalho que visa à cidadania, o que é anunciado nos Parâmetros Curriculares 
Nacionais como um trabalho que dialoga com a transversalidade e com a interdisciplinaridade. Além disso, a degradação ambiental pode ser objeto de estudo numa perspectiva inter e transdisciplinar, em que os conhecimentos matemáticos podem ser trabalhados e a formação da consciência crítica dos alunos desenvolvida.

\section{Metodologia E Descrição Do Estudo}

O presente estudo, que é parte de uma tese de doutorado, decorre de uma formação continuada em educação matemática e ambiental proporcionada a professores de matemática, com o objetivo de verificar se o desenvolvimento dessa formação daria subsídio teórico-prático que influenciasse nas práticas de sala de aula desses professores com a temática do meio ambiente.

O artigo apresenta os resultados da aplicação de diversas situações-problema que integram o conhecimento matemático e o meio ambiente, trazendo análises referentes à mudança de atitudes dos alunos diante das questões ambientais e percepções a respeito da aprendizagem.

As atividades desta pesquisa foram desenvolvidas em 2015 com 8 professores de matemática do município de São Sebastião do Caí e seus respectivos alunos nas 4 escolas municipais do município que apresentam os anos finais do Ensino Fundamental e nas 2 escolas estaduais.

Os sujeitos da pesquisa estão distribuídos abaixo, conforme observamos no Quadro 01.

\begin{tabular}{|c|c|c|}
\hline Denominação professor & Número de turmas & $\begin{array}{c}\text { Número de alunos } \\
\text { participantes }\end{array}$ \\
\hline S1 & 3 & 90 \\
\hline S2 & 4 & 99 \\
\hline S3 & 2 & 53 \\
\hline S4 & 3 & 62 \\
\hline S5 & 3 & 51 \\
\hline S6 & 3 & 99 \\
\hline S7 & 3 & 29 \\
\hline S8 & 1 & 59 \\
\hline
\end{tabular}

Quadro 1: Sujeitos da pesquisa

Fonte: A pesquisa

A distribuição das escolas participantes e os respectivos professores envolvidos, constam no Quadro 2. 


\begin{tabular}{|c|c|}
\hline Escolas & Professores Envolvidos \\
\hline Escola Municipal Gal.David Canabarro & S1 e S2 \\
\hline Escola Municipal General São José & S3 e S4 \\
\hline Escola Municipal Alencastro Guimarães & S6 \\
\hline Escola Municipal Dr. Alberto Pasqualini & S7 \\
\hline Escola Estadual São Sebastião & S8 \\
\hline Escola Estadual Felipe Camarão & S \\
\hline
\end{tabular}

Quadro 2: Escolas participantes Fonte: A Pesquisa

As situações-problema foram construídas pelos professores durante a formação, pois os temas ambientais apareciam com pouca frequência ou eram inexistentes nos livros didáticos de matemática dos anos finais do Ensino Fundamental utilizados por esses educadores. Elas foram elaboradas para promover uma aprendizagem que levasse os alunos a ampliar os significados dos conteúdos estudados, principalmente no que diz respeito ao uso do conhecimento escolar em situações fora da escola e principalmente alertar para as questões ambientais.

Foram realizados diversos encontros para a busca de informações em meios eletrônicos, jornais e revistas locais para a elaboração de problemas que explorassem a preservação da fauna e flora, produção de resíduos sólidos, poluição, área de preservação permanente - APP, vegetação, recursos hídricos e energia. Os conteúdos matemáticos envolvidos na abordagem das temáticas foram: estatística, regra de três, porcentagem, proporção, operações com números naturais, perímetro, áreas e medidas de comprimento, massa e volume.

Foram elaboradas 80 situações-problema, que foram trabalhadas pelos professores e suas respectivas turmas de forma impressa ou escritas no quadro nos anos em que atuavam.

As situações apresentadas aos alunos eram exploradas pelos professores durante o desenvolvimento dos conteúdos matemáticos que estavam sendo estudados na ocasião, pois não eram trabalhadas de forma distante dos conceitos matemáticos estudados no momento por cada turma. Elas foram resolvidas na maioria das vezes em grupos, pois a resolução exigia muita discussão, questionamentos e tomada de decisões para a solução dos problemas que eram propostos.

Além dos problemas construídos previamente e que eram apresentados aos alunos de forma impressa ou escrita no quadro, havia muitos deles que decorriam de situações geradas através de pesquisas de campo realizadas dentro da escola, nos arredores ou no entorno da 
residência dos alunos. A figura 1 representa três momentos ${ }^{3}$ de uma situação desenvolvida em aula, originada de uma pesquisa realizada sobre os resíduos produzidos na escola durante uma semana, na qual os alunos fizeram a medida do lixo produzido por semana e a estimativa da produção por mês e ano. O resultado trouxe o envolvimento de todos os setores da escola na busca de uma menor produção de lixo e a conscientização da importância da separação dos materiais encontrados nele.

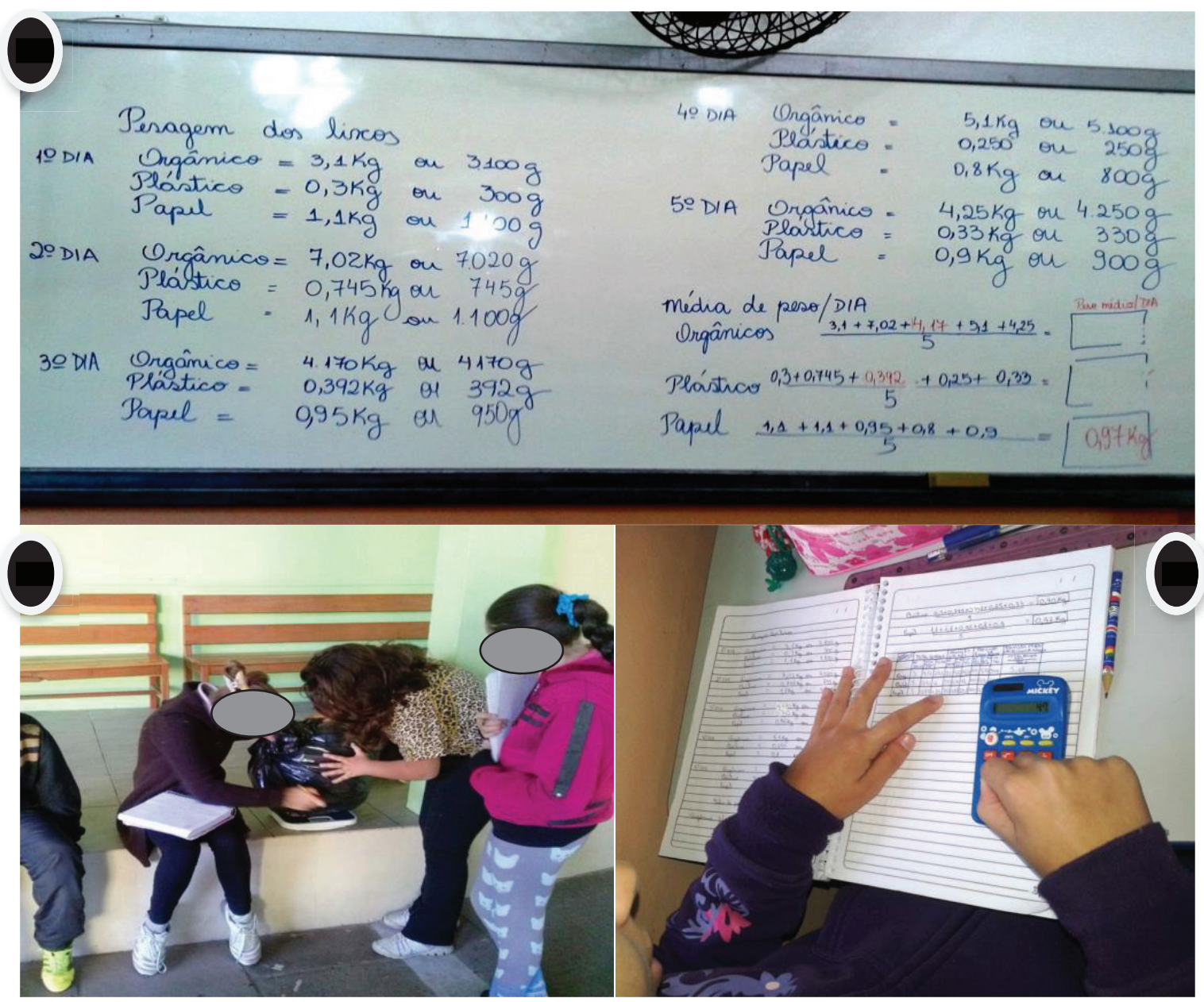

Figura 1: Situação gerada de pesquisa de campo Fonte: A Pesquisa

Em alguns casos, os problemas gerados por meio de pesquisas de campo, levaram outros professores de outras disciplinas a participar do tema proposto, por meio de atividades extras, como foi o caso dos problemas envolvendo a temática da fauna. A situação-problema decorria de uma pesquisa de campo para identificar os animais que a comunidade tinha em suas residências, gerando gráficos e utilizando porcentagens para tabular os dados e informar sobre

\footnotetext{
${ }^{3} \mathrm{O}$ momento 1 é o de coleta e pesagens dos resíduos produzidos na escola durante uma semana. No momento 2 , os alunos organizam os dados coletados e realizam cálculos nos seus cadernos de estimativas de produção mensal e anual de resíduos gerados pela escola e o momento 3, o professor e os alunos expõem e analisam os dados elaborados.
} 
a pesquisa. $\mathrm{Na}$ escola do professor S6, o professor de Ciências resolveu participar e organizou um concurso de fotografias com os animais de estimação, já o professor de Português promoveu um concurso de redação com o título "Meu animal é demais".

Grande parte das situações que eram impressas para serem resolvidas, envolviam problemas locais buscados no cotidiano dos alunos e fundamentados pelos órgãos governamentais. Um exemplo, foi o que apontava por meio de ilustrações, o índice de qualidade das águas dos bairros do município onde ocorreu o estudo e das cidades que com ele fazem divisa.

Muitos dos problemas sofreram adaptações para a realidade dos alunos e da escola. Um exemplo está na Figura 2, que registra uma atividade realizada em uma escola que apresenta uma horta suspensa devido às enchentes no bairro. Os alunos do $6^{\circ}$ ano tabularam os chás que cultivavam na horta e, em seguida, construíram gráficos de colunas para representá-los.

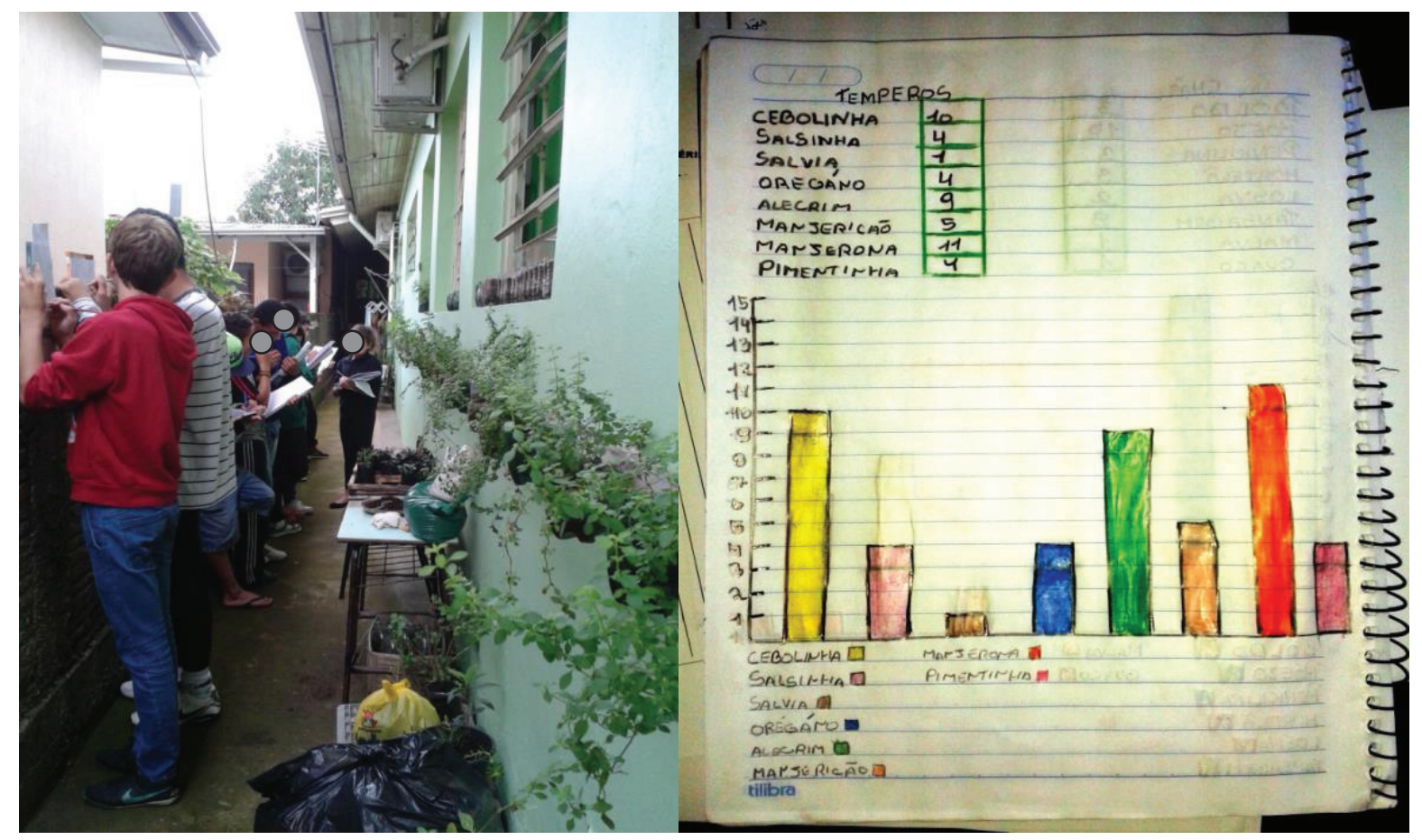

Figura 2: Situação-problema adaptada Fonte: A Pesquisa

Os materiais utilizados na elaboração das análises referentes às contribuições das situações-prboblema para a formação da consciência ambiental nos alunos e a sensibilização sobre os cuidados com o meio ambiente foram os questionários diagnósticos aplicados aos alunos.

O questionário diagnóstico foi aplicado, antes e após o desenvolvimento das situaçõesproblema, para verificar se o estudo de temas ambientais com matemática nas aulas, sensibilizava os alunos sobre a importância dos cuidados com o meio ambiente e auxiliava na 
formação do aluno-cidadão, consciente da importância da preservação da natureza. Eles foram respondidos em grupos nas mesmas composições que foram utilizadas na execução das tarefas dos problemas.

\section{Resultados E Análises}

Para analisar a influência que as situações-problema provocaram nos estudantes, foram aplicados questionários aos alunos antes do início da resolução das situações-problema e após o desenvolvimento das tarefas. O comparativo por meio dos questionários, permitiu obter informações relevantes a respeito do comportamento dos alunos em relação ao tema em estudo.

Com os questionamentos realizados no término das atividades com as situaçõesproblemas, observou-se que um número significativo de alunos obteve um crescimento no vocabulário, pois eles expressaram suas opiniões a respeito, mostraram uma ampliação nos conhecimentos e, também, mudaram suas convicções e opiniões referentes aos cuidados com o meio ambiente. O percentual de evolução ou mudança de opinião dos alunos distribuído pelas questões levantadas e as escolas participantes do estudo está expresso no Quadro 3.

\begin{tabular}{|l|c|c|}
\hline \multicolumn{1}{|c|}{ Questões } & $\begin{array}{c}\text { Escola Alencastro } \\
\text { Guimarães }\end{array}$ & Esc. David Canabarro \\
\hline $\begin{array}{l}\text { Se a escola apresenta algum rio, arroio ou lago } \\
\text { poluído próximo dela, o que sua turma ou escola } \\
\text { poderiam fazer para amenizar o problema } \\
\text { identificado? }\end{array}$ & 75 & 80 \\
\hline $\begin{array}{l}\text { Você está fazendo a sua parte no controle do } \\
\text { desperdício da água dentro da escola? E na sua } \\
\text { casa? Explique }\end{array}$ & 80 & 100 \\
\hline $\begin{array}{l}\text { Você concorda com o procedimento do destino } \\
\text { final do esgoto produzido na escola? }\end{array}$ & 80 & 60 \\
\hline $\begin{array}{l}\text { Na sua casa a água é tratada? Se não for, quais } \\
\text { providências que são tomadas pelos pais para } \\
\text { que ela não contamine a família? }\end{array}$ & 60 & 60 \\
\hline $\begin{array}{l}\text { Você acha que economizar água potável pode } \\
\text { ajudar a evitar a falta de energia elétrica no } \\
\text { Brasil? Explique.? }\end{array}$ & 50 & 68 \\
\hline \multicolumn{1}{c|}{ Questões } & Escola São José \\
\hline $\begin{array}{l}\text { Você acha importante a escola apresentar horta? } \\
\text { Por quê? }\end{array}$ & Guimarães & 51 \\
\hline $\begin{array}{l}\text { Sabemos que todo o lixo produzido no pátio e } \\
\text { nas salas é coletado pelas responsáveis da } \\
\text { limpeza, mas nesses ambientes, você e seus } \\
\text { colegas contribuem com a limpeza? Explique. }\end{array}$ & 60 & 45 \\
\hline $\begin{array}{l}\text { Você acha que a água tratada utilizada para o } \\
\text { regamento da horta e do jardim é apropriada? Dê } \\
\text { sua opinião a respeito ou uma sugestão para o } \\
\text { uso racional da água no regamento de hortas e } \\
\text { jardins. }\end{array}$ & 50 & 34 \\
\hline
\end{tabular}




\begin{tabular}{|c|c|c|c|c|}
\hline $\begin{array}{l}\text { Se sua escola está localizada em uma área de } \\
\text { APP, por que isso pode ter acontecido? }\end{array}$ & \multicolumn{2}{|c|}{80} & \multicolumn{2}{|c|}{73} \\
\hline $\begin{array}{l}\text { Por que é importante preservarmos as áreas de } \\
\text { APP? }\end{array}$ & \multicolumn{2}{|c|}{100} & \multicolumn{2}{|c|}{85} \\
\hline Questões & $\begin{array}{c}\text { Esc. A. } \\
\text { Guimarães } \\
\end{array}$ & $\begin{array}{c}\text { Esc. A. } \\
\text { Pasqualini } \\
\end{array}$ & $\begin{array}{c}\text { Esc. D. } \\
\text { Canabarro } \\
\end{array}$ & $\begin{array}{l}\text { E.E. São } \\
\text { Sebastião }\end{array}$ \\
\hline $\begin{array}{l}\text { Você sabe para onde vai o lixo da tua escola? } \\
\text { Você acha adequado o destino que é dado? }\end{array}$ & 100 & 80 & 100 & 100 \\
\hline $\begin{array}{l}\text { Sua escola faz separação de lixo? Se sim, o que } \\
\text { faz com os recicláveis? }\end{array}$ & 80 & 50 & 80 & 100 \\
\hline $\begin{array}{l}\text { O que você faz com o lixo de sua casa? Faz a } \\
\text { separação adequada? }\end{array}$ & 0 & 75 & 40 & 80 \\
\hline $\begin{array}{l}\text { Sabemos que todo o lixo produzido no pátio e } \\
\text { nas salas é coletado pelas responsáveis da } \\
\text { limpeza, mas nesses ambientes, você e seus } \\
\text { colegas contribuem com a limpeza? Explique. }\end{array}$ & 20 & 0 & 0 & 0 \\
\hline Questões & \multicolumn{2}{|c|}{ Esc. Alberto Pasqualine } & \multicolumn{2}{|c|}{ Esc. David Canabarro } \\
\hline $\begin{array}{l}\text { Você analisa a potência dos aparelhos elétricos } \\
\text { da sua casa? }\end{array}$ & \multicolumn{2}{|c|}{50} & \multicolumn{2}{|c|}{34} \\
\hline $\begin{array}{l}\text { Quando você ou alguém da sua família compra } \\
\text { um eletrodoméstico, é observada a potência } \\
\text { desse aparelho ou se consome menos energia? } \\
\text { Como você faz isso? }\end{array}$ & \multicolumn{2}{|c|}{50} & \multicolumn{2}{|c|}{51} \\
\hline $\begin{array}{l}\text { Você costuma deixar aparelhos ligados ou } \\
\text { lâmpadas acesas quando não há ninguém em } \\
\text { casa? }\end{array}$ & \multicolumn{2}{|c|}{0} & \multicolumn{2}{|c|}{17} \\
\hline $\begin{array}{l}\text { Você já observou a conta de luz de sua casa? } \\
\text { Sabe como é calculado o valor a pagar? Tem } \\
\text { interesse em aprender para fazer um controle dos } \\
\text { gastos? }\end{array}$ & \multicolumn{2}{|c|}{100} & \multicolumn{2}{|c|}{68} \\
\hline $\begin{array}{l}\text { A sua família está adotando formas para evitar o } \\
\text { desperdício de energia elétrica? Explique. }\end{array}$ & \multicolumn{2}{|c|}{50} & \multicolumn{2}{|c|}{68} \\
\hline $\begin{array}{l}\text { Vir para a escola caminhando ou de ônibus, pode } \\
\text { contribuir para diminuirmos a poluição? Por } \\
\text { quê? }\end{array}$ & \multicolumn{2}{|c|}{75} & \multicolumn{2}{|c|}{63} \\
\hline $\begin{array}{l}\text { O que pensa a respeito das aves que estão } \\
\text { engaioladas? }\end{array}$ & \multicolumn{2}{|c|}{17} & \multicolumn{2}{|c|}{20} \\
\hline
\end{tabular}

Quadro 3: Percentual de evolução ou mudança de opinião dos alunos distribuídos pelas questões levantadas e as escolas participantes

Fonte: A pesquisa

Segundo Skovsmose (2001), é objetivo da Educação Matemática tornar os alunos capazes de utilizar a Matemática no dia a dia, empregando-a para a compreensão da realidade. Para o autor, a Matemática, deve formar alunos com capacidade de argumentação, reflexivos e também compromissados com a realidade e isso ficou demonstrado com o resultado expressivo apresentado no quadro anterior.

Para Cool (2006), as práticas sociais criam ambientes favoráveis à aprendizagem de matemática, mas essa aprendizagem matemática, pode ser tomada como a própria participação em práticas sociais. Para o autor, as atividades de ensino devem promover aquisições de conhecimento mais significativas e que desencadeiem uma atitude favorável para realizá-las, permitindo o maior número de relações entre os distintos conteúdos. Essas atividades também 
devem facilitar a compreensão de uma realidade que nunca se apresenta compartimentada.

Em alguns casos, os alunos não manifestaram evoluções ou mudança de opinião, e isso se deve ao fato desses alunos já apresentarem uma consciência ambiental desenvolvida. Fato percebido no questionário aplicado inicialmente e, portanto, não houve essa mudança de opinião, ou eles, ainda, não ampliaram suas convicções. De forma pouco relevante, ocorreram casos de estudantes que não se sensibilizaram pelas propostas de trabalho desenvolvidas, logo não manifestaram progressos, que foram percebidos no comparativo de respostas dos questionários referentes à preocupações e conhecimentos sobre temas ambientais.

Como já citado, muitos alunos ao expressarem suas opiniões no início e, após, no término das atividades com situações-problema, as modificaram completamente, com respostas que apresentavam preocupações ambientais e conscientização sobre o assunto.

Essa percepção de modificação de respostas e de opiniões, pode ser exemplificada pelos comentários que constam no Quadro 4.

\begin{tabular}{|c|c|c|}
\hline Questionamento & Antes & Depois \\
\hline $\begin{array}{l}\text { O que você faz com o lixo de sua casa? } \\
\text { Faz a separação adequada? }\end{array}$ & $\begin{array}{l}\text { Não fazemos separação na } \\
\text { nossa casa. }\end{array}$ & $\begin{array}{l}\text { Separamos seco do orgânico e o } \\
\text { óleo eu coloco numa garrafa e } \\
\text { vendo para uma mulher que faz } \\
\text { sabão de óleo. }\end{array}$ \\
\hline $\begin{array}{l}\text { Você acha que a água tratada utilizada } \\
\text { para o regamento da horta e do jardim } \\
\text { é apropriada? Dê sua opinião a respeito } \\
\text { ou uma sugestão para o uso racional da } \\
\text { água no regamento de hortas e jardins. }\end{array}$ & $\begin{array}{l}\text { Sim, é apropriada porque } \\
\text { assim as frutas vão crescer e } \\
\text { nós podemos comer. }\end{array}$ & $\begin{array}{l}\text { Não porque eles podem usar a água } \\
\text { da chuva. Podemos economizar } \\
\text { mais água. }\end{array}$ \\
\hline $\begin{array}{l}\text { Você concorda com o procedimento do } \\
\text { destino final do esgoto produzido na } \\
\text { escola? }\end{array}$ & $\begin{array}{l}\text { Sim, porque ele não vaza e } \\
\text { não contamina as águas. }\end{array}$ & $\begin{array}{l}\text { Não, porque corre pela rua e vai } \\
\text { parar num arroio e que vão para um } \\
\text { lugar cheio de barro. }\end{array}$ \\
\hline $\begin{array}{l}\text { Vir para a escola caminhando ou de } \\
\text { ônibus, pode contribuir para } \\
\text { diminuirmos a poluição? Por quê? }\end{array}$ & $\begin{array}{l}\text { Não porque tem a fumaça } \\
\text { que sai do ônibus. }\end{array}$ & $\begin{array}{l}\text { Sim, os que moram longe se } \\
\text { vierem num ônibus único contribui } \\
\text { mais do que cada um vir para a } \\
\text { escola com o próprio carro e os que } \\
\text { moram perto vem caminhando. }\end{array}$ \\
\hline
\end{tabular}




\begin{tabular}{|l|l|l|}
\hline $\begin{array}{l}\text { Quando você ou alguém da sua família } \\
\text { compra uño } \\
\text { observada a potência desse aparelho ou } \\
\text { se consome menos energia? Como você } \\
\text { faz isso? }\end{array}$ & $\begin{array}{l}\text { Sim, olhando em um adesivo de } \\
\text { informação que geralmente vem } \\
\text { colado no eletrodoméstico ligado } \\
\text { em energia. }\end{array}$ \\
\hline $\begin{array}{l}\text { Você já observou a conta de luz de sua } \\
\text { casa? Sabe como é calculado o valor a } \\
\text { pagar? Tem interesse em aprender para } \\
\text { fazer um controle dos gastos? }\end{array}$ & $\begin{array}{l}\text { Já observamos mas não } \\
\text { sabemos como é calculado o } \\
\text { valor a pagar. Alguns de nós } \\
\text { têm interesse em fazer o } \\
\text { controle do gasto e outras } \\
\text { não }\end{array}$ & $\begin{array}{l}\text { Sim, aprendemos e estamos } \\
\text { calculando agora usando fórmulas } \\
\text { simulador. }\end{array}$ \\
& & \\
\hline
\end{tabular}

Quadro 4: Comentários por questionamento

Fonte: A pesquisa

Percebeu-se que alunos modificaram completamente a resposta dada ou se comprometeram em reformular os hábitos, como é o caso do questionamento sobre a verificação da potência nos eletrodomésticos que são comprados. Inicialmente, diziam que não verificavam e, com o desenvolvimento do projeto, passaram a dizer que sim: “[...] sim, olhando em um adesivo de informação que geralmente vem colado no eletrodoméstico ligado em energia."

Por meio da resolução de problemas, é possível desenvolver a autoconfiança dos alunos, levando-os ao aprofundamento dos conceitos já existentes e ampliando a desenvoltura na solução de situações diversas do dia a dia. À medida que a compreensão dos alunos se torna mais profunda e mais rica, sua habilidade em usar matemática para resolver problemas aumenta consideravelmente.

As mudanças de opiniões apresentadas, mostraram que a Matemática, aliada às questões ambientais, colaborou para a formação de cidadãos com responsabilidade socioambiental, confirmando o que Skovsmose (2001) declara, ao afirmar que nas situações-problema, deveriam ser apresentados aos alunos temas que fossem relevantes, significativos e que abrissem espaço para questionamentos políticos e sociais, pois o trabalho com situações matemáticas contextualizadas desperta nos alunos a vontade de solucioná-las e instiga a investigação.

De acordo com os PCN (1998), o conhecimento matemático formalizado precisa ser necessariamente transferido e isso será possível pela contextualização desse saber. Essa contextualização pode atuar como ação motivadora da aprendizagem, quando o professor dá significado a um conceito da matemática formal ou quando traz um conteúdo de interesse ou 
que faça parte do contexto dos alunos, pois é mostrada a importância do assunto que está sendo estudado e suas aplicações, motivando-os para aprender.

Para uma parte dos alunos, não houve mudança de opinião referente aos questionamentos, mas como citado anteriormente, houve um engrandecimento do conhecimento e da consciência ambiental dos estudantes. Eles demonstraram uma ampliação de argumentos e de posicionamentos referentes às questões ambientais, com adoções de posturas de preservação e de controle do desperdício, que podem ser exemplificadas no Quadro

5 .

\begin{tabular}{|c|c|c|}
\hline Questionamento & Antes & Depois \\
\hline $\begin{array}{l}\text { Você está fazendo a sua } \\
\text { parte no controle do } \\
\text { desperdício da água } \\
\text { dentro da escola? E na } \\
\text { sua casa? Explique }\end{array}$ & $\begin{array}{l}\text { Sim, quando estamos lavando a } \\
\text { louça desligamos a torneira para } \\
\text { ensaboar. }\end{array}$ & $\begin{array}{l}\text { Sim, na escola nós reutilizamos a água do } \\
\text { bebedouro para a horta suspensa e outros fins. Na } \\
\text { nossa casa nós reaproveitamos a água da máquina } \\
\text { de lavar, a água da chuva para lavar pisos, } \\
\text { bicicletas, carro e lavamos louça com a torneira } \\
\text { desligada. }\end{array}$ \\
\hline $\begin{array}{l}\text { Você acha importante a } \\
\text { escola apresentar horta? } \\
\text { Por quê? }\end{array}$ & $\begin{array}{l}\text { Sim, achamos importante porque } \\
\text { para o bem da nossa saúde }\end{array}$ & $\begin{array}{l}\text { Eu acho importante porque terão alimentos mais } \\
\text { saudáveis, sem conservantes e venenos, mas não } \\
\text { temos horta. Precisamos comer frutas e legumes, } \\
\text { não somente na nossa casa mas na escola também. }\end{array}$ \\
\hline $\begin{array}{l}\text { Vir para a escola } \\
\text { caminhando ou de } \\
\text { ônibus, pode contribuir } \\
\text { para diminuirmos a } \\
\text { poluição? Por quê? }\end{array}$ & Sim, pois o ônibus contribui & $\begin{array}{l}\text { Nós fizemos uma pesquisa e vimos que a maioria } \\
\text { dos alunos vem de ônibus e a minoria vem a pé, } \\
\text { mas a gente acha que podemos diminuir a poluição } \\
\text { com esta medida, porque ajuda a melhorar o meio } \\
\text { ambiente. Vinte pessoas caminhando e não vindo } \\
\text { de carro diminui a poluição. }\end{array}$ \\
\hline $\begin{array}{l}\text { Você acha que } \\
\text { economizar água potável } \\
\text { pode ajudar a evitar a } \\
\text { falta de energia elétrica } \\
\text { no Brasil? Explique. }\end{array}$ & $\begin{array}{l}\text { Sim, porque a nossa luz vem da } \\
\text { água. }\end{array}$ & $\begin{array}{l}\text { Sim, pois se tiver mais água as hidrelétricas } \\
\text { funcionariam melhor, pois com o aumento da } \\
\text { quantidade de água as turbinas funcionariam com } \\
\text { maior força iria produzir mais energia elétrica. }\end{array}$ \\
\hline $\begin{array}{l}\text { Porque é importante } \\
\text { preservarmos as áreas de } \\
\text { APP? }\end{array}$ & Não sei & $\begin{array}{l}\text { Porque essas áreas contribuem com o meio } \\
\text { ambiente. Nelas espécies sobrevivem aos } \\
\text { impactos ambientais e a devastação que o homem } \\
\text { vem fazendo ao longo dos tempos }\end{array}$ \\
\hline $\begin{array}{l}\text { Você sabe para onde vai } \\
\text { o lixo da tua escola? Você } \\
\text { acha adequado o destino } \\
\text { que é dado? }\end{array}$ & Vai para o lixão. & $\begin{array}{l}\text { Vai para Minas do Leão. Um componente não } \\
\text { acha adequado porque ele vai ser aterrado e ficar } \\
\text { na natureza e a água que sai do lixo vão para a água } \\
\text { que tomamos. Os outros componentes acham } \\
\text { adequados. }\end{array}$ \\
\hline
\end{tabular}

Quadro 5: Ampliação de argumentos e posicionamentos referentes as questões ambientais Fonte: A pesquisa

Ao longo das atividades dos jogos, os alunos foram provocados a analisar frequentemente os resultados obtidos, com o objetivo de promover a reflexão.

Além da reflexão contínua dos alunos, observou-se que eles mostraram muita dedicação e participação durante a realização das atividades. Acredita-se, que diversos motivos 
favoreceram esse comportamento nos alunos, dentre eles, a abordagem de temas contextualizados e o trabalho em grupo.

Para Pais (2008), a expansão do real objetivo da educação escolar se dá por meio da contextualização do saber, pois, dessa forma, o aluno compreende a relação do conteúdo a ser estudado com um cenário que pode ser compreendido

Os estudantes perceberam que a Matemática pode ser um mecanismo de análise e de interpretação da realidade, pois os conceitos matemáticos foram aplicados por eles em situações concretas, levando-os ao estudo de outras áreas como, no caso, o meio ambiente.

De acordo com os resultados apresentados, os alunos obtiveram uma evolução significativa no desenvolvimento da consciência ambiental. Percebeu-se que os estudantes souberam se posicionar de forma crítica sobre os temas estudados, pois apresentaram alternativas de conservação, cuidados com o meio ambiente e principalmente, se situaram num contexto real com as particularidades locais, dando contribuições com ações efetivas de manejo e de conservação ambiental.

Para os professores envolvidos na aplicação das situações-problema, é possível e necessário trabalhar com educação ambiental nas aulas de matemática. Para eles, mesmo no princípio sendo complexo e difícil devido a falta de formação para um trabalho com temas ambientais, a temática foi mais uma maneira de contextualizar a matemática, dando sentido aos conteúdos e envolvendo os alunos na construção do conhecimento, utilizando dados da realidade na prática de sala de aula. Eles também declararam que continuarão promovendo essa integração de conhecimentos e ampliando a relação entre a Educação Matemática e a Ambiental, pois é possível dar um novo olhar para a matemática e contribuir com a conscientização ambiental dos alunos.

Ao serem explorados nas aulas de matemática os temas ambientais, não foram apenas propostos aos alunos instrumentos para compreensão de fenômenos, mas também oportunizados subsídios através do uso da matemática, para que os estudantes percebam o seu verdadeiro papel como cidadãos e transformadores sociais.

A interação entre o conhecimento matemático e as questões ambientais na busca de uma melhor compreensão do ambiente em que vivemos, faz com que o aprendizado da matemática e do saber ambiental seja relevante e transforme o comportamento das pessoas, com o intuito de promover uma melhor qualidade de vida.

A compreensão e a tomada de decisões diante de questões sociais, políticas e ambientais dependem da leitura e da interpretação de informações complexas, que podem incluir, por 
exemplo, dados estatísticos e índices divulgados pelos meios de comunicação. Ou seja, para exercer a cidadania, é necessário saber calcular, medir, raciocinar, argumentar, tratar informações estatisticamente, entre outros tantos conhecimentos. Portanto, o ensino da matemática necessita formar o aluno como um todo, utilizando o conhecimento matemático integrado às demais áreas de conhecimento, a partir da realidade e do contexto em que o aluno está inserido

\section{Considerações finais}

A Matemática escolar deve deixar de assumir uma postura neutra, baseando-se no fato de tratar-se de uma ciência que lida com números, uma ciência exata e, por isso, raramente questionada. Portanto, é fundamental esse momento, em que o professor pode levar o estudante a não apenas manusear os algoritmos, e sim, torná-lo capaz de estabelecer relações entre os resultados e o contexto, levando a realidade para um questionamento.

Já é consenso entre os educadores matemáticos que a capacidade de pensar, raciocinar e resolver problemas deve constituir um dos principais objetivos do estudo da Matemática. É importante destacar que o conteúdo trabalhado com o aluno deve ser significativo e que o estudante deve sentir que é importante saber aquilo para a sua vida em sociedade, ou que lhe será útil para entender o mundo em que vive. Portanto, para que o aluno veja a Matemática como um assunto útil e prático e possa apreciar o seu poder, precisa perceber que ela está presente em praticamente tudo e é aplicada para resolver problemas do mundo real.

A combinação da Matemática com as questões ambientais mostrou ser uma direção promissora que instiga o interesse dos estudantes em aprender Matemática, ao mesmo tempo, tornando-os cidadãos críticos e conscientes da problemática ambiental que os rodeia.

\section{Referências}

BRASIL.Secretaria de Educação Fundamental. Parâmetros curriculares nacionais: terceiro e quarto ciclos: apresentação dos temas transversais. Brasília: MEC/SEF, 1998.

. Secretaria de Educação Fundamental. Parâmetros curriculares nacionais: matemática. Brasília: MEC, 1998.

Búrigo, R. Integração entre educação matemática e educação ambiental: Uma proposição no contexto da gestão do conhecimento. Tese (Doutorado em Engenharia e Gestão do Conhecimento). Florianópolis: Universidade Federal de Santa Catarina, 2009.

CALDEIRA, A. D. Revista Profissão Docente.Uberaba, v.1, n.1, p.24-35, jan/abr. 2001. 
CIFUENTES, José Carlos; PRESTINI, S. A. M. A transversalidade e a educação matemática. In: MENEGHETTI, Renata Cristina Geromel (org.). Educação matemática: vivências refletidas. São Paulo: Centauro, 2006. p. 35-55.

COOL, C. (2006). O construtivismo na sala de aula. São Paulo: Ática.

COSTA, R.G.A. Um olhar crítico sobre a educação ambiental na formação de professores em uma instituição de ensino superior gaúcha. Revista Eletrônica do Mestrado em Educação Ambiental. Rio Grande, v. 22, p. 177-187, jan./jul. 2009.

DANTE, Luiz Roberto. Criatividade e resolução de problemas na prática educativa matemática. Rio Claro: Instituto de Geociências e Ciências Exatas, Tese de Livre Docência, 1988.

DANTE, Luiz Roberto. Matemática: 1 ${ }^{\mathrm{a}}$ série. $1^{\mathrm{a}}$ edição. São Paulo: Ática, 2004.

DANTE, Luiz Roberto. Didática da resolução de problemas de matemática. São Paulo: Ática, 1991.

DIAS, G. F. de. A Situação da Educação Ambiental no Brasil é Fractal. In: MEC ; SEF, Panorama da educação ambiental no ensino fundamental / Secretaria de Educação Fundamental - Brasília :, 2001. 149 p.: il.

ECHEVERRÍA, M.D.P.P.; POZO, J.I. Aprender a resolver problemas e resolver problemas para aprender. In: A solução de problemas: aprender a resolver, resolver a aprender. Juan IgnacioPozo. Porto Alegre: Artmed, 1988.

FREIRE, P. A pedagogia da autonomia: saberes necessários à prática educativa. São Paulo: Paz e Terra, 1996.

LOPES, Antonio José et al. Resolução de problemas: observações a partir do desempenho dos alunos. A educação matemática em revista. Revista da Sociedade Brasileira de Educação Matemática (SBEM) Ano II - n..$^{\circ} 3$ e $2^{\circ}$ semestre, 1994 p. 33-40.

MACCARINI, J. I. C. M. Contribuições da formação continuada em Educação Matemática à prática do professor. Dissertação (Curso de Mestrado em Educação) - Universidade Tuiuti do Paraná. Curitiba, 2007.

MEYER, Mônica. Além das quatro paredes. VII Seminário de Ensino de Biologia FAE-USP. São Paulo: USP, 2000.

PAIS, L. C. Transposição Didática. In: Machado, S. D. A. Educação Matemática: uma introdução. São Paulo: EDUC, 2008.

NOVICKI, Victor. Diagnóstico SocioCulturalAmbiental. Rio de Janeiro, 2006. Disponível em: $<$ http://www.educacaoambiental.pro.br>. Acesso em: 01 dez. 2012.

ONUCHIC, Lourdes de la Rosa. Ensino-aprendizagem de matemática através da resolução de problemas. In: BICUDO, Maria Aparecida Viggiani (Org.). Pesquisa em educação matemática: concepções e perspectivas. São Paulo: Unesp, 1999.

SATO, M. Educação ambiental. São Carlos: Rima, 2003.

SKOVSMOSE, O. Educação matemática crítica.Campinas: Papirus, 2001.

Autêntica, 2001.

Didática da matemática: uma análise da influência francesa. Belo Horizonte: 
SMOLE, K.S.; DINIZ, M.I.; MILANI, E. Jogos de matemática do $6^{\circ}$ ao $9^{\circ}$ ano. Cadernos do Mathema. Porto Alegre: Artmed, 2007.

SMOLE, K.C.S. e CENTURIÓN, M. A matemática de jornais e revistas.

RPM n. ${ }^{\circ} 20,1 .^{\circ}$ quadrimestre de 1992.

UNESCO (Organização das Nações Unidas para a Educação, a Ciência e a Cultura). Educação Ambiental: as grandes orientações da Conferência de Tbilisi. Brasília: IBAMA, 1997. 